\title{
İstenmeyen perioperatif hipotermi bakım algoritması
}

\author{
Aylin GÜÇLÜ 國, Mevlüde KARADAĞ ${ }^{1}{ }^{1}$
}

\section{ÖZ}

Çalışmanın amacı kanıta dayalı bilgiler doğrultusunda, hemşirelerin kliniklerde İstenmeyen Perioperatif Hipotermi (IPH) bakımına yönelik karar vermesi için, yol gösterici bir araç olarak İPH bakım algoritmasının oluşturulmasıdır. Türkçe ve İngilizce olarak 2010-2020 yılları arasını kapsayacak şekilde Pubmed, Cohrane, Google Akademi, CIHNAL, Science Direct, Clinical Key veri tabanlarında: Hipotermi (hypothermia), istenmeyen (inadvertent, unplanned, not planned, unintended), perioperatif (perioperative), rehber (guideline), protokol (protocol), algoritma (algorithm) anahtar kelimeleri ile tarama yapılmıştır. Kanıt düzeyi yüksek rehberler, sistematik derlemeler ve meta analizler değerlendirme kapsamına alınmıştır. Dahil edilme kriterlerine uyan, 6 rehber ve 2 sistematik derlemeden elde edilen bilgiler doğrultusunda, girișimler ameliyat öncesi, ameliyat sırası ve ameliyat sonrası șeklinde gruplandırılmıș ve İPH'nin önlenmesi ve bakımına yönelik algoritma oluşturulmuştur. İPH'nin bakımına yönelik algoritma kullanımı hemşirelerin hızlı ve doğru karar vererek ameliyat öncesinde, sırasında ve sonrasında gelişebilecek komplikasyonların engellenmesi açısından önemlidir. Bu anlamda algoritma kullanımı klinik karar vermeyi kolaylaş̧ırıp kanıt düzeyinde girişimlerle bakım sağlamada hemşireler için önemli bir araçtır. Geliştirilen IPH bakım algoritmasının kliniklerde uygulanarak geçerlik güvenirliğinin yapılması ve hemşirelik girişimlerine yönelik algoritmaların arttırılması önerilmektedir.

Anahtar Kelimeler: Hipotermi; perioperatif; algoritma; hemşirelik.

\section{ABSTRACT}

\section{Inadvertent perioperative hypothermia care algorithm}

The aim of the study was to develop an Inadvertent Perioperative Hypothermia (IPH) care algorith in line with evidence-based information as a guiding tool for nurses to make decisions about IPH care in clinics. To cover the period 2010-2020, in Pubmed, Cohrane, Google Academy, CIHNAL, Science Direct, Clinical Key databases: Hypothermia, unwanted (inadvertent, unplanned, not planned, unintended), perioperative, guideline, protocol, algorithm key words were searched in Turkish and English. Guidelines with a high level of evidence, systematic reviews and meta-analyzes were included in the evaluation. In accordance with the inclusion criteria, in line with the information obtained from 6 guides and 2 systematic reviews, the interventions were grouped as preoperative, intraoperative and postoperative, and an algorithm was developed for the prevention and care of IPH. The use of algorithms for the care of IPH is important for nurses to make fast and correct decisions to prevent complications that may occur before, during and after surgery. In this context, the use of algorithms is an important tool for nurses in facilitating clinical decision making and providing care with evidence-based interventions. It is recommended to apply this IPH care algorithm in clinics, to make the validity and reliability and to increase the algorithms for nursing interventions.

Keywords: Hypothermia; perioperative; algorithm; nursing. 


\section{Gİiș}

İstenmeyen periopretif hipotermi (İPH); anestezi öncesi 1 saatten başlayıp anestezi sonrası ilk 24 saate kadar geçen süre içinde vücut sıcaklığının $36^{\circ} \mathrm{C}$ 'nin altına düşmesi olarak ifade edilmektedir (1-4). Ameliyat sırası dönemde cilt ve batının açılması, IV sıvıların kullanımı, irrigasyon sıvıları ve inhale gazlar, hastaların doğrudan sıcaklık kaybı yaşamasına neden olmaktadır. Anestezinin erken dönemi ise vücut iç sıcaklığının hızlıca azalmasına, sicaklığın periferik ve santral bölgelerde yeniden dağılmasına neden olur $(3,5)$. İPH cerrahi işlem geçiren hastalarda yaygın olarak görülen bir problemdir $(3,4)$. Yapılan çalışmalara bakıldığında; Scholten ve arkadaşları (6) $\% 11,7$, Yi ve arkadaşları (7) \%39,9, Frisch ve arkadaşları (8) ise \%43,9 oranında IPH tespit etmiştir. IPH ayrica cerrahi alan enfeksiyonu, ilaç metabolizmasının gecikmesi, kan kaybının artması ile birlikte daha fazla kan transfüzyonu gereksinimi ve oksijen ihtiyacının artması, anestezi sonrası derlenme süresinin uzaması, hastanın termal konforunun bozulması, bulantı ve kusmanın artması, mortalitenin artması ve maliyetlerde artış gibi komplikasyonlara neden olmaktadır $(2,9)$.

Hemşireler, cerrahi süreç boyunca hastalara bakma ve hastaları izlemede birincil rol oynar. $\mathrm{Bu}$ nedenle, hemşirelerin IPH riskini arttıran faktörler, hipoterminin olumsuz etkileri ve önlenmesine yönelik girişimler konusunda bilgi sahibi olması cerrahi hastasının güvenliğini sağlamada önemli bir faktördür (10). Association of periOperative Registered Nurses (AORN) üyelerinin İPH bilgi düzeylerini incelediği bir çalışmada hemşirelerin büyük bir çoğunluğunun vücut sıcaklığının alt ve üst değerlerini yanlış tanımladığı bulunmuştur (3). Tamer ve Karadağ (9) çalışmasında hemşirelerin \%70,0'nin, hemşirelik eğitimi sırasında İPH hakkında bilgi aldığı fakat sadece \%3,5'nin İPH yönünden hastalarını değerlendiği belirlenmiştir. $\mathrm{Bu}$ çalışmalar hemşirelerin İPH'ye ilişkin bilgi eksikliği olduğunu, IPH'yi yeterince değerlendirmediği ve buna ilişkin gerekli bakım girişimlerinde bulunmadığını göstermektedir.

Hemşirelerin klinik karar vermeyi kolaylaştıran yollar kullanması, hızlı ve etkin karar vermelerini sağlayarak bakım kalitesinin artmasına katkıda bulunmaktadır. (12). İPH'nin yönetimi için bakım paketi kullanılan bir çalışmada, kanıt düzeyinde belirlenmiş hemşirelik girişimlerinin uygulanması ile İPH kaynaklı komplikasyonların azaldığı, maliyetlerin de \%88,1 oranında düştüğü tespit edilmiştir (9). Algoritmalar da, kanıt düzeyinde bilgiler doğrultusunda hazırlanan, öğrenmeyi kolaylaştırıp, eleştirel düşünmeyi sağlayan ve sistematik bir şekilde bakımın planlanıp eksiksiz olarak uygulanmasını ve yeniden değerlendirilmesine olanak tanıyan pratik ve etkin bir yol sağlar (13). Hye-rim ve arkadaşlarının (14) yaptığı bir çalışmada; perkütan koroner girişim sonrası hemşirelik girişimleri için geliştirilen algoritmanın kullanılması ile femoral ponksiyon bölgesinde kanama ve sırt ağrısında azalma olduğu tespit edilmiştir. Huzur evinde kalan yaşlilarda disfajinin önlenmesinde kanıta dayalı bakım algoritması kullanılan bir çalışmada, algoritma kullanımından sonra aspirasyon riskinin azaldığı ve disfajiye bağlı yaşam kalitesinin anlamlı oranda arttığg belirlenmiştir (15).
İPH bakım algoritmasına yönelik, Amerikan Perianestezi Hemşireler Derneği (The American Society of PeriAnesthesia Nurses- ASPAN), ameliyat öncesi, ameliyat sırası ve ameliyat sonrası döneme ilişkin, bir sonraki bakım girişimi için ne yapılacağı belirtilmeden, bir algoritma oluşturulmuştur (16). Fakat ülkemizde IPH'ye ilişkin geliştirilmiş bir bakım algoritmasına ulaşılamamıştır. İPH'nin yönetiminde kanıt düzeyinde bilgiler doğrultusunda hazırlanan bakım algoritmalarının, hemşirelerin sistematik bir şekilde bakım vermesini sağlayarak, hasta sonuçlarının iyileşmesine katkı sağlayacağı düşünülmektedir. $\mathrm{Bu}$ bağlamda çalışma; kanıta dayalı bilgiler doğrultusunda İPH bakım algoritmasının oluşturulması amacıyla yapılmıştır. Böylece kliniklerde İPH bakımına yönelik hemşirelerin klinik karar vermesinde bir yol gösterici araç olması hedeflenmektedir.

İPH algoritmasını Pubmed, Cohrane, Google Akademi, CINAHL, Science Direct, Clinical Key veri tabanlarından, Türkçe ve İngilizce anahtar kelimelerle; hipotermi (hypothermia), istenmeyen (inadvertent, unplanned, not planned, unintended), perioperatif (perioperative), rehber (guideline), protokol (protocol), algoritma (algorithm) tarama yapılarak algoritma oluşturulmuştur. Tarama yapılırken; pediatrik (pediatric), sezaryen cerrahisi, (caesaren section), planlı hipotermi (planned hypothermia) terapötik hipotermi (therapeutic hypothermia), kalp cerrahisi (cardiac surgery), ortopedik cerrahi (ortopedic surgery) kelimeleri dişlanma kriterlerine eklenmiştir.

Tarama kapsamında 2010-2020 yılları arasında ulusal ve uluslararası dergilerde yayınlanmış ilgili kanıt düzeyi yüksek rehberler, sistematik derleme, meta analizler değerlendirme kapsamına alınmıştır. Randomize kontrollü çalışmalar geliştirilen rehberler tarafından meta analize dahil edilip kullanıldığı için tekrar değerlendirme kapsamına alınmamıştır. İH bakım algoritması yapılan literatür değerlendirmesi sonucunda 6 rehber ve 2 sistematik derlemenin çalışma kriterlerine uygun olduğu belirlenmiştir (4,16-22) (Şekil 1).

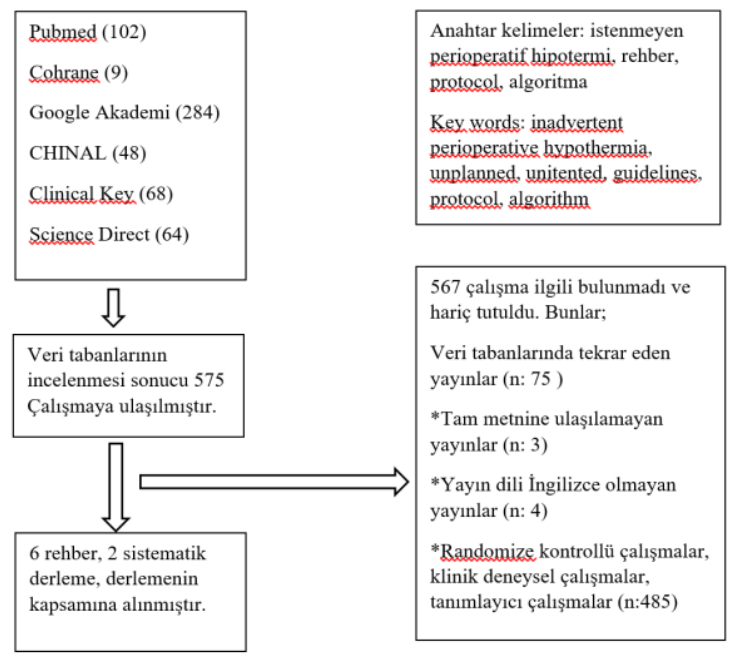

Şekil 1. Literatür akış şeması

IPH bakım algoritması ameliyat öncesi, sırası ve sonras1 dönem olmak üzere üç gruba ayrılmıştır. Ameliyat 
sonrası dönemde ise kendi içerisinde derlenme ünitesi ve cerrahi klinik olmak üzere iki başlıkta ele alınmıştır. Ameliyat öncesi 12, ameliyat sirası 16, ameliyat sonrası 19 bakım uygulaması olmak üzere algoritma toplamda 47 girişim basamağından oluşmaktadır. Hemşirelerin yapması gereken girişimler belirli bir akış içinde sıralanarak gösterilmiştir (Şekil-2, Şekil-3, Şekil-4, Şekil5).

\section{İstenmeyen Perioperatif Hipotermi Bakım Algoritması}

Literatür taraması sonucunda geliştirilen bakım algoritması ameliyat öncesi sırası ve sonrası olmak üzere üç bölümden oluşmaktadır.

\section{Ameliyat Öncesi Dönem}

Ameliyat öncesi dönemde hastanın İPH risk faktörleri (Tablo 1), hipotermi belirti bulguları (Tablo 2) ve hastanın üşüyüp üşümediği değerlendirilmelidir (Şekil 2) $(4,16,19,21,22)$. Ardından hastanın iç vücut sıcaklığ ölçülmelidir $(4,16,19,21)$. İç vücut sıcaklığını yansıtan bölgeler yüzeyel vücut sıcaklığını yansıtan bölgelerden daha güvenilir bölgelerdir (Tablo 3) (23). Bu yüzden vücut sıcaklığı ölçümlerinde iç vücut sıcaklığı bölgelerine öncelik verilmelidir (25). İç vücut sıcaklığı ölçümü için kullanılan bölgeler; pulmoner arter, özofagus, rektum, timpanik membran, mesane bölgeleri iken; yüzeyel vücut sıcaklığı ölçüm bölgeleri deri, oral kavite ve aksilla bölgeleridir (19,24,25).

Hastanın vücut sıcaklığı normal değer aralığında olmasına rağmen hasta üşüdüğünü söylüyorsa pasif ısıtma yöntemi kullanılmalıdır (16,22). Vücut sıcaklığı normal değerlerde $\left(36-38^{\circ} \mathrm{C}\right)$ ise; anestezi indüksiyonundan 20-30 dk. önce aktif 1sitmaya başlanmalıdır (4,18,19,21). Ameliyathanede bekleme salonunun olup olmadığ 1 değerlendirilmeli, eğer yoksa hastanın ameliyathaneye transferinden 20-30 dk. önce klinikte aktif ısıtma yöntemi kullanılmaya başlanmalıdır. Lau ve arkadaşlarının (26) randomize kontrollü olarak yaptığı çalışmada müdahale grubu, anestezi indüksiyonundan $30 \mathrm{dk}$. önce aktif 1sitma yöntemi ile 1sitılmaya başlanmış ve kontrol grubuna göre ameliyat sırası dönemde hipotermiye daha az maruz kalmıştır. Yapılan bir diğer çalışmada ise; anestezi indüksiyonundan $30 \mathrm{dk}$. önce aktif 1sitma yöntemi ile 1sıtılmaya başlanan hastaların \%13'ünde İPH tespit edilirken, kontrol grubunda bu oran \%43 olarak tespit edilmiştir (27).

Kliniklerde vücut sıcaklığı ölçüm yolu olarak timpanik membran tercih edilmeli (Tablo 3), timpanik termometre klinikte yoksa deri, oral kavite, aksilla bölgelerinden biri tercih edilmelidir $(24,25,28)$. Tamasaki ve arkadaşlarının (29) yaptığı çalışmada timpanik membran sıcaklık ölçümü ile özofagus sıcaklık ölçüm sonuçları birbirine yakın sonuçlar vermiş ve timpanik membran ölçüm yolunun perioperatif süreç boyunca kullanılabileceği önerilmiştir. Kızıl ötesi alın termometresi ölçümü ile kızıl ötesi timpanik termometre ölçümünün karşılaştırıldığı bir çalışmada timpanik ölçümün daha güvenilir bir yol olduğu bulunmuştur (31). Farklı vücut sıcaklığı ölçüm yollarının normal değer aralıkları birbirinden farklı olduğu için, hangi ölçüm yolunun kullanıldığı kayıt edilmelidir.
Hastanın vücut sıcaklığı ancak normal aralıkta $\left(36-38^{\circ} \mathrm{C}\right)$ ise ameliyathaneye transferi sağlanmalı $(4,16,19,20,22)$, transfer sırasında 1sıtma yöntemi kullanılmaya devam edilmeli $(4,16,19,21,22)$ ve ameliyathane hemşiresine teslim sirasinda hastaya yapilan termal uygulamalar hakkında bilgi verilmelidir (Şekil 2) (16-18,46).

\section{Ameliyat Sırası Dönem}

Hastanın ameliyathaneye transferi sağlandıktan sonra, ameliyathane odası ortam sicaklığg kontrol edilmelidir. Bunun için kesin bir değer verilmemekle birlikte literatür değerlendirmesi sonucu ameliyathane ortam sıcaklığının en az $21-24^{\circ} \mathrm{C}$ olmasi önerilmektedir $(4,19,21)$. İntravenöz sıvilar (500 $\mathrm{ml}$ ve daha fazlası) ve kan ürünlerinin $37^{\circ} \mathrm{C}$ ye kadar ısıtılması sağlanmalıdır $(4,19)$. Tüm yıkama sıvılarının kaç dereceye kadar ssıtılması ile ilgili standart bir değer verilmemiştir. Fakat yapılan literatür değerlendirmesi sonucunda yıkama sıvılarının $33-41^{\circ} \mathrm{C}$ aralığında 1sıtılması önerilmektedir (Şekil 3) (4,17,19,21). Campbell ve arkadaşlarının (17) İH'nin önlenmesinde yıkama ve intravenöz sıvıların 1sitılmasına yönelik yaptıkları sistematik derlemede; toplamda 1250 katılımcının olduğu 24 çalışma değerlendirilmiş ve sıvıların $37-41^{\circ} \mathrm{C}$ aralığında 1 sıtıldığı tespit edilmiş olup kanıt düzeyi ise orta olarak belirlenmiştir.

Vücut sıcaklığı anestezi indüksiyonundan önce ve cerrahi girişimin sonuna kadar her 15-30 dk. da bir ölçülmelidir (4). Rektum, özofagus, pulmoner arter ve mesane bölgelerinden birinde sicaklık probu varsa vücut ölçümü için öncelikli olarak bu bölgeler tercih edilmeli, eğer bu bölgelerden birinde sıcaklık monitörizasyonu mümkün değilse timpanik membrandan ölçüm yapılması sağlanmalıdır $(24,30)$. Hangi ölçüm yolu kullanıldıysa kayit edilmelidir.

Vücut sıcaklığ $36^{\circ} \mathrm{C}$ 'nin altında ise; ameliyathane kritik olay formu doldurulmalı ve ameliyathanedeki sağlık ekibine bilgi verilmelidir. Vücut sıcaklığı en az $36^{\circ} \mathrm{C}$ oluncaya kadar anestezi indüksiyonun ertelenmesi sağlanmalıdır $(4,19,21,22)$. Anestezi indüksiyonun başlaması ile vücut sıcaklığı $36,5-37^{\circ} \mathrm{C}$ olacak şekilde, cerrahi girişim boyunca aktif 1sitma yöntemi kullanılmalıdır (Şekil 3) (4,16,19-22).

Ameliyat süresi $30 \mathrm{dk}$. ve üzerinde ise veya hastada İPH risk faktörü varsa vücut sıcaklığı $36,5-37^{\circ} \mathrm{C}$ aralığında tutulacak şekilde cerrahi girişim boyunca aktif 1sıtma yöntemi uygulanmalıdır $(4,17,19)$. Ancak ameliyat süresi $30 \mathrm{dk}$. altı ve İPH risk faktörü yoksa herhangi bir 1sıtma yönteminin kullanılmasına gerek yoktur (4).

Ameliyat sırası boyunca 1sı kaybını önlemek için hastanın yeterince örtülmesi sağlanmalıdır $(4,20)$. İşlem sonrası hastanın derlenme ünitesine transferi sağlanmalı, derlenme ünitesi hemşiresine teslim sırasında hastaya yapılan termal uygulamalar hakkında bilgi verilmelidir (Şekil 3) (3,16-18,46).

Ameliyat Sonrası Dönem Derlenme Ünitesi

Ameliyat sonrası hasta derlenme ünitesine geldiğinde İPH riski (Tablo 1), hipotermi belirti bulguları (Tablo 2) ve hastanın üşüyüp üşümediği tekrar değerlendirilmedir $(4,16,19,21,22)$. IPH riski veya hipotermi belirti bulguları varsa sağlık ekibine haber verilmelidir $(4,16)$. Hastanın vücut sıcaklığı derlenme ünitesine kabulde ve kliniğe transferine kadar her 15 dk.' da bir ölçülmelidir $(4,21,22)$. 


\section{AMELIYYT ÖNCESI DÖNEMDE İPH BAKIM ALGORITMASI}

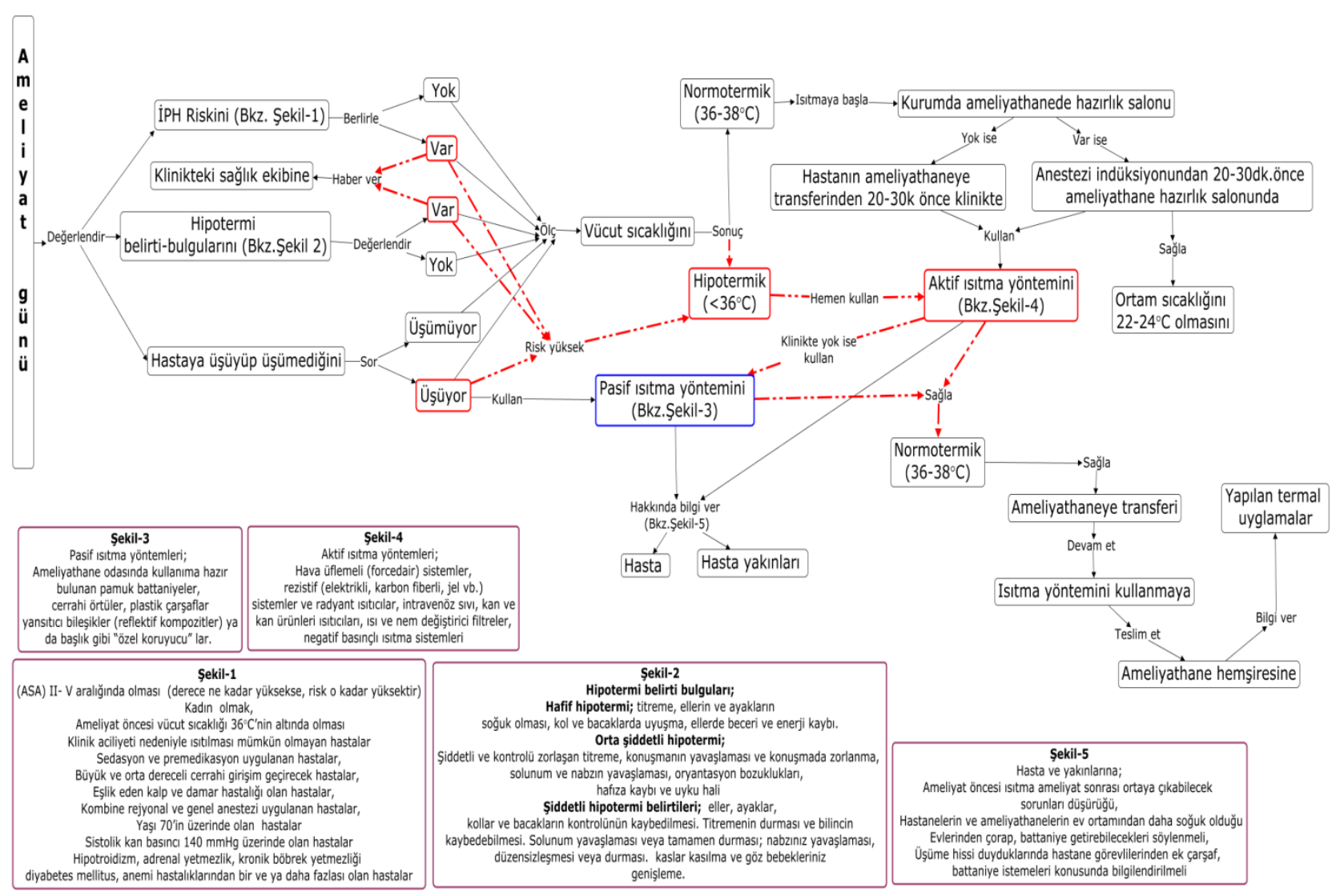

Şekil 2. Ameliyat öncesi dönem İPH bakım algoritması

\section{AMELIYAT SIRASI DÖNEMDE İPH BAKIM ALGORTİMASI}

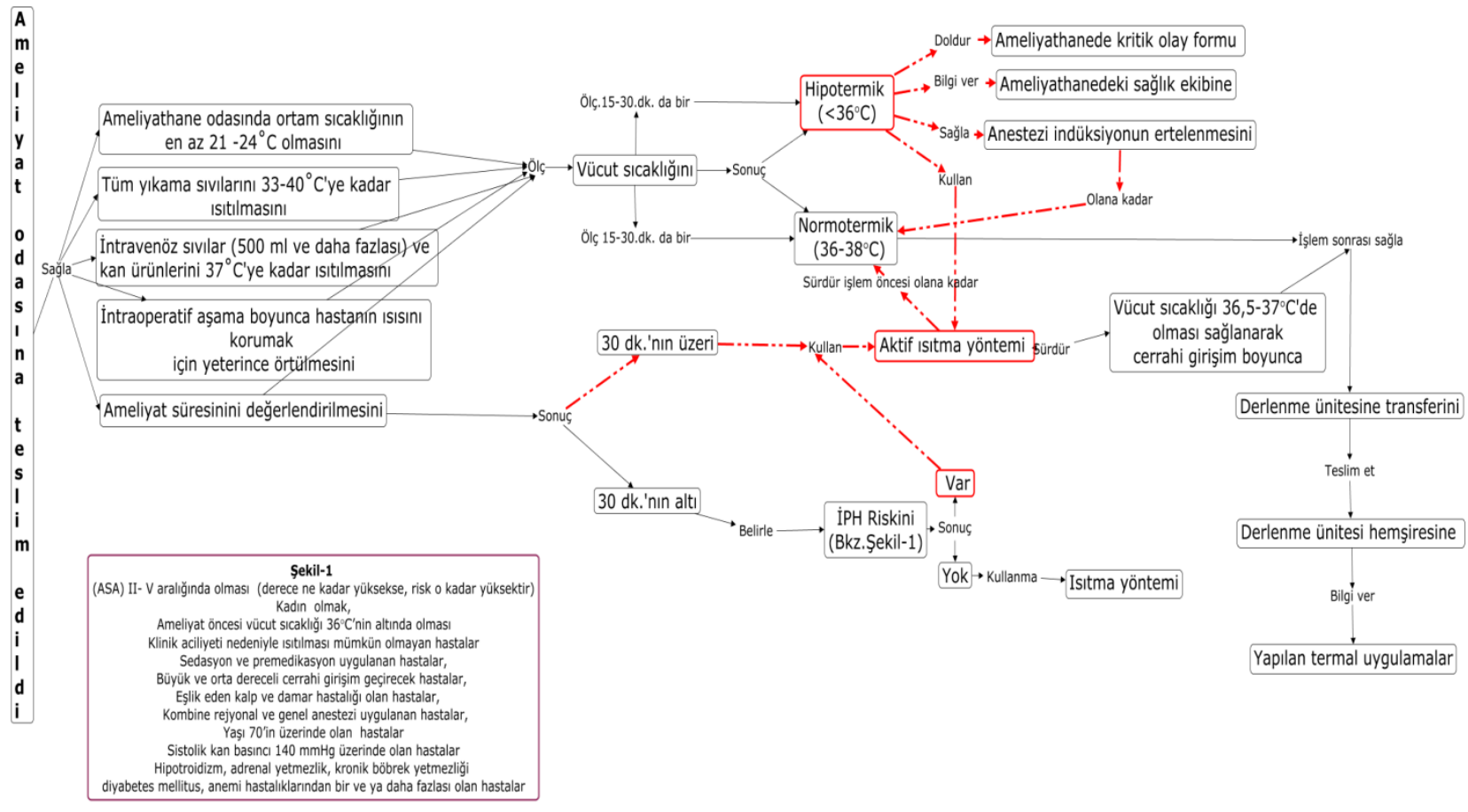

Şekil 3. Ameliyat sırası dönem İPH bakım algoritması 
DERLENME ÜNİTESİNDE İPH BAKIM ALGORİTMASI
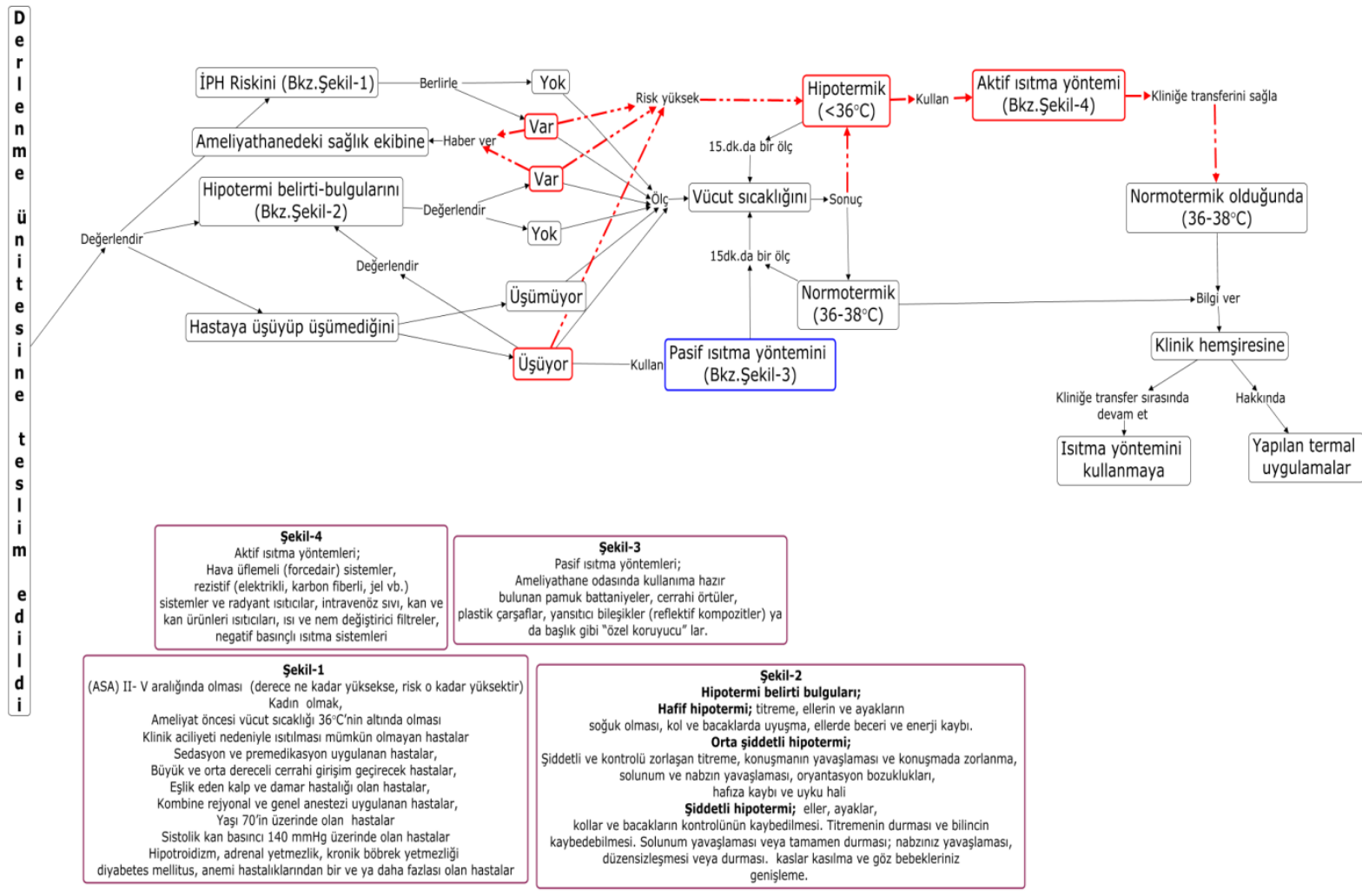

Şekil 4. Ameliyat sonrası dönem derlenme ünitesinde İPH bakım algoritması

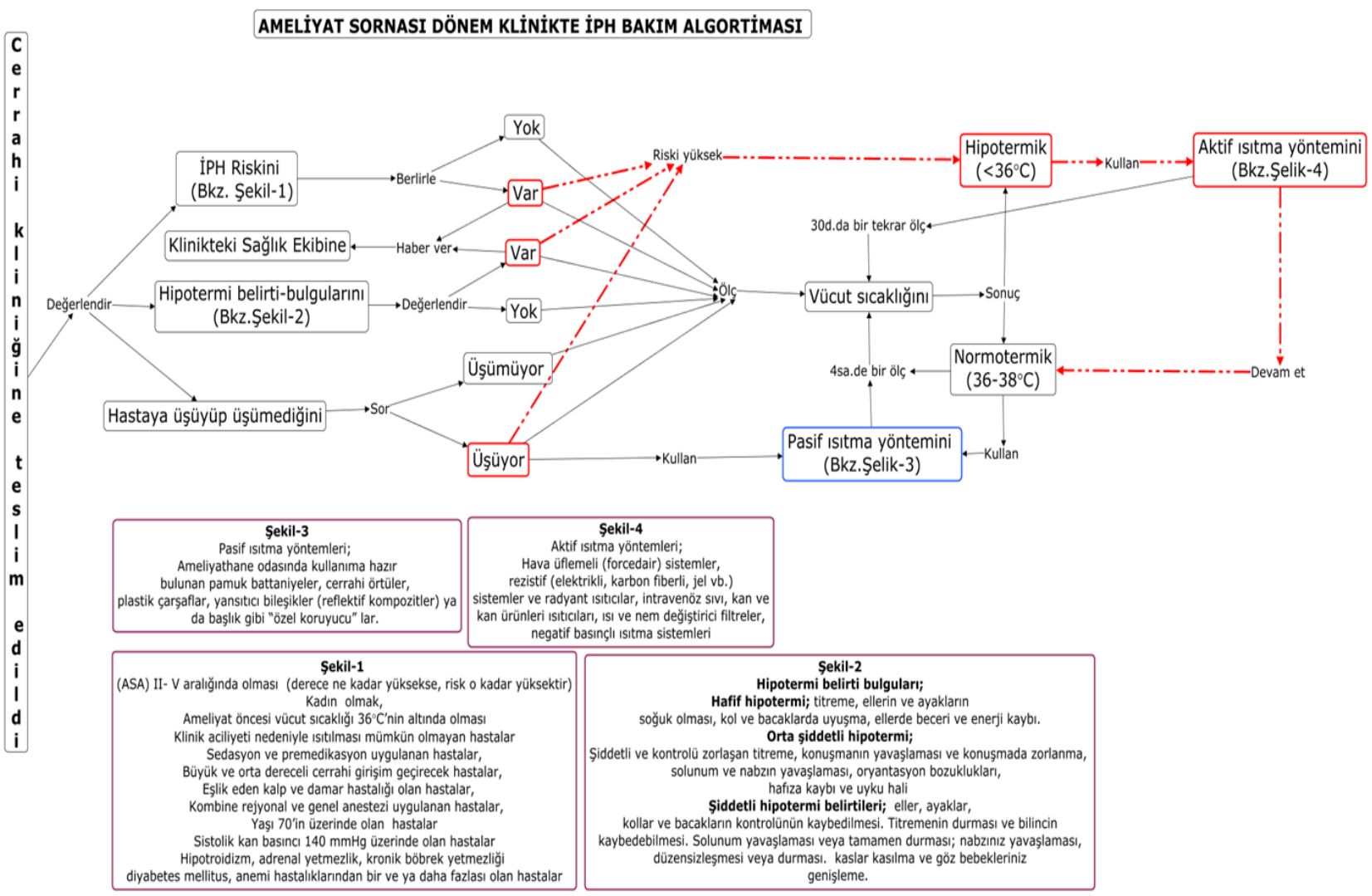

Şekil 5. Ameliyat sonrası dönem klinikte İPH bakım algoritması 
Tablo 1. İPH'de risk faktörleri ve nedenleri

\begin{tabular}{|c|c|}
\hline İPH Risk Faktörleri & Nedenleri \\
\hline ASA skorunun II ve üzerinde olması & $\begin{array}{l}\text { ASA (American Society of Anesthesiologists) skorunun yüksek olması sistemik düzeyde sorunların } \\
\text { artması ile termoregülasyonun sağlanmasını zorlaştırır (33). }\end{array}$ \\
\hline 70 yaş ve üzeri yaşa sahip olmak & $\begin{array}{l}\text { Hipotalamusun, somatik ve otonom sinir sistemi işlevleri yavaşladığı için termoregülasyon yavaşlar } \\
\text { (35). }\end{array}$ \\
\hline Kadın cinsiyet & $\begin{array}{l}\text { İnsanlar vücut (kas) kütlesine dayalı 1S1 üretir ve 1sıyı yüzey alanına göre dağıtır. Kadınlarda vücut } \\
\text { yüzey alanı vücut kütlesine oranla daha büyüktür ve deri altı yağ içeriği daha fazladır. Bu yüzden } \\
\text { termoregülasyona karşı tepkileri erkeklerden farklıdır (35). }\end{array}$ \\
\hline $\begin{array}{l}\text { Vücut sıcaklığının } 36^{\circ} \mathrm{C} \text { 'nin altında } \\
\text { olması }\end{array}$ & Hipotermi için bir risk faktörüdür (4). \\
\hline Büyük ve orta dereceli cerrahiler & Cerrahi süresi uzadıkça hem ısı üretimi azalır hem de 1sı kaybı artar (36). \\
\hline $\begin{array}{lll}\text { Sedasyon } & \text { ve } & \text { premedikasyon } \\
\text { uygulanması } & & \end{array}$ & $\begin{array}{l}\text { Anestezik ajanlar ve kullanılan sedatifler, vazokonstriksiyon cevabını bloke ederek 1s1 kaybının } \\
\text { şiddetlenmesine neden olur (9). }\end{array}$ \\
\hline $\begin{array}{l}\text { Kombine rejyonel ve genel anestezi } \\
\text { uygulanması }\end{array}$ & $\begin{array}{l}\text { Analjezi seviyesinin altında kalan bölgede periferal vazokonstriksiyon engellendiği için sıcaklık kaybı } \\
\text { gerçekleşir (5). Anestezi vücut iç sıcaklığının azalmasına, sıcaklığın periferik ve santral bölgelerde } \\
\text { yeniden dağılmasına neden olur (3). }\end{array}$ \\
\hline $\begin{array}{l}\text { Sistolik kan basıncının } 40 \mathrm{mmHg} \text { 'nın } \\
\text { üzerinde olması }\end{array}$ & $\begin{array}{l}\text { Hipotermi ile noradrenalin salınımı artması periferal vazokonstriksiyona neden olur bu durumda } \\
\text { hipertansiyonu şiddetlendirir (37). }\end{array}$ \\
\hline $\begin{array}{l}\text { Cerrahi patoloji } \text { dışında } \quad \text { kalp } \\
\text { hastalığının olması }\end{array}$ & $\begin{array}{l}\text { Hipotermi, adrenerjik cevabın salınımı sonucu katekolemin salınıma neden olmakta bu durumda } \\
\text { vazokonstriksiyon, taşikardi ve hipertansiyon gibi komplikasyonların ortaya çıkmasına neden } \\
\text { olmaktadır (38). }\end{array}$ \\
\hline Hipotroidizm & Bazal metabolizma hızı düştüğü için soğuğa karşı intolerans gelişir (39). \\
\hline Adrenal yetmezlik & $\begin{array}{l}\text { Hipotalamo-hipofizer adrenal aksta bozukluklara neden olarak adrenal kortekste fonksiyon kayıplarına } \\
\text { neden olabilmektedir (40). }\end{array}$ \\
\hline Anemi & $\begin{array}{l}\text { Kırmızı kan hücrelerinin eritropoezisi için demir ve eritropoetin gereklidir. Demirin, soğukla ilişkili } \\
\text { strese karşı koyabilme becerisini kontrol eden bağı̧̧ılık işlevi ve termoregülasyonu güçlendirme } \\
\text { üzerinde olumlu etkileri vardır (41). }\end{array}$ \\
\hline Diyabetes mellitus & $\begin{array}{l}\text { Hemodinamik dengesizlik ve vazokonstrüksiyon gibi sebeplerle subkutan insülin emiliminin } \\
\text { bozuklukları ortaya çıabilmektedir (42). }\end{array}$ \\
\hline Kronik böbrek yetmezliği & Eritropoetin salınımı azalarak anemiye neden olmaktadır (43). \\
\hline Travma hastaları & $\begin{array}{l}\text { Hemorajik şok, çevresel maruziyetler ve tedavi sonuçlarının (anestezik ilaçlar ve intravenöz sıvılar) } \\
\text { kombinasyonundan kaynaklanan faktörler nedeniyle hipotermi riski taşımaktadırlar (44). }\end{array}$ \\
\hline Yanık hastaları & $\begin{array}{l}\text { Termal yaralanma sonrası meydana gelen fizyolojik değişiklikler termal homeostazisi bozar ve hastaları } \\
\text { hipotermiye yatkın hale getirir (45). }\end{array}$ \\
\hline
\end{tabular}


Tablo 2. Hipotermi belirti bulguları

\begin{tabular}{|l|l|}
\hline Hipotermi derecesi & Belirti- bulgular \\
\hline Hafif düzeyde & $\begin{array}{l}\text { Titreme, ellerin ve ayakların soğuk olması, kol ve bacaklarda uyuşma, ellerde enerji ve beceri } \\
\text { kaybı (36). }\end{array}$ \\
\hline Orta düzeyde & $\begin{array}{l}\text { Şiddetli ve kontrolü zorlaşan titreme, konuşmanın yavaşlaması ve konuşmada zorlanma, solunum } \\
\text { ve nabzın yavaşlaması, oryantasyon bozuklukları, hafıza kaybı ve uyku hali (36,46). }\end{array}$ \\
\hline Şiddetli düzeyde & $\begin{array}{l}\text { Eller, ayaklar, kollar ve bacakların kontrolünün kaybedilmesi, titremenin durmas1 ve bilincin } \\
\text { kaybedilmesi, solunumun yavaşlaması veya tamamen durmasi; nabzın yavaşlaması, } \\
\text { düzensizleşmesi veya durması, kaslarda kasılma ve göz bebeklerinde genişlemedir (36,46). }\end{array}$ \\
\hline
\end{tabular}

Tablo 3. Vücut sicaklığı ölçüm bölgeleri

\begin{tabular}{|c|c|c|c|c|c|}
\hline $\begin{array}{l}\text { İç vücut } \\
\text { sıcaklığı } \\
\text { ölçüm } \\
\text { bölgesi }\end{array}$ & $\begin{array}{l}\text { Ölçüm } \\
\text { aralığı }\end{array}$ & Kullanımı & $\begin{array}{c}\text { Yüzeyel } \\
\text { vücut } \\
\text { sıcaklığı } \\
\text { ölçüm bölgesi }\end{array}$ & $\begin{array}{l}\text { Ölçüm } \\
\text { aralığ1 }\end{array}$ & Kullanımı \\
\hline $\begin{array}{l}\text { Pulmoner } \\
\text { arter }\end{array}$ & $36-38^{\circ} \mathrm{C}$ & $\begin{array}{l}\text { İç vücut sıcaklığı ölçümü için } \\
\text { genellikle altın standart yöntem olarak } \\
\text { kabul edilir fakat pulmoner arter } \\
\text { kataterinin yerleştirilmesi invazif } \\
\text { işlem gerektiren ve yüksek riskli bir } \\
\text { prosedür olduğu için her hasta için } \\
\text { uygulanabilir değildir (35). }\end{array}$ & Aksilla & $36-37^{\circ} \mathrm{C}$ & $\begin{array}{l}\text { Takip zorluğu (yerinden oynaması), ajite } \\
\text { olan hastalarda kullanılamaması, uzun } \\
\text { uygulanma zamanına gereksinim } \\
\text { duyulması, ciltte sıcaklık artı̧̧ sonucu } \\
\text { oluşan vazokonstrüksiyona ve terlemeye } \\
\text { bağlı olarak gerçekte olduğundan daha } \\
\text { düşük değerler gösterebilmesi nedeni ile } \\
\text { kullanımı zordur (24). }\end{array}$ \\
\hline Özofagus & $36-38^{\circ} \mathrm{C}$ & $\begin{array}{l}\text { Özofagus ile ölçüm yolu, pulmoner } \\
\text { arter ile eşit sonuç verdiği için iç } \\
\text { vücut sıcaklığı ölçümü için tercih } \\
\text { edilebilir, fakat uygun prob yerleşimi, } \\
\text { ölçüm sırasında hastaya verilen sıkıntı } \\
\text { ve buna bağlı maliyet ve zaman kaybı } \\
\text { gibi dezavantajları vardır (47). }\end{array}$ & Oral kavite & $36,5-37,5^{\circ} \mathrm{C}$ & $\begin{array}{l}\text { Hastalar için uygulanması kolaydır ve } \\
\text { ortam sıcaklığından fazla etkilenmez. Sıvı } \\
\text { ve gıda alımından sigaradan, sakız } \\
\text { çiğneme ve oksijen alımından etkilenir. } \\
\text { Ağız içi ameliyat ve travma geçirmiş } \\
\text { hastalarda, epileptik hastalarda, bilinci } \\
\text { kapalı ve iş birliği yapamayan hastalarda } \\
\text { kullanılmamalıdır (22). }\end{array}$ \\
\hline Rektum & $37-38^{\circ} \mathrm{C}$ & $\begin{array}{l}\text { Rektumu çevreleyen büyük doku } \\
\text { kütlesi, çevre ortam sıcaklığından } \\
\text { korunan sabit bir sıcaklık ölçümü } \\
\text { sağlar. Fakat rektal sıcaklığın iç vücut } \\
\text { sıcaklığındaki ani ve hızlı değişimlere } \\
\text { tepki verme kabiliyeti sınırlıdır (48). }\end{array}$ & Deri & $36,5-37,5^{\circ} \mathrm{C}$ & $\begin{array}{l}\text { Ucuzdur, sürekli değer elde edilmesini } \\
\text { sağlar, invazif bir işlem gerektirmez. Fakat } \\
\text { çevresel isılardan etkilenebilir (21). }\end{array}$ \\
\hline
\end{tabular}


Tablo 3. Vücut sıcaklığı ölçüm bölgeleri (devamı)

\begin{tabular}{|c|c|c|c|c|c|}
\hline $\begin{array}{l}\text { İç vücut } \\
\text { sıcaklığı } \\
\text { ölçüm } \\
\text { bölgesi }\end{array}$ & $\begin{array}{l}\text { Ölçüm } \\
\text { aralığı }\end{array}$ & Kullanımı & $\begin{array}{l}\text { Yüzeyel vücut } \\
\text { sıcaklığı } \\
\text { ölçüm bölgesi }\end{array}$ & $\begin{array}{l}\text { Ölçüm } \\
\text { aralığı }\end{array}$ & Kullanımı \\
\hline Mesane & $36-38^{\circ} \mathrm{C}$ & $\begin{array}{l}\text { Mesane katateri takılması kolay ve } \\
\text { çıkma riski az olduğu için iç vücut } \\
\text { sıcaklığını ölçmede tercih edilen bir } \\
\text { yöntemdir. Fakat anüri ve oligüri } \\
\text { hastalarında kullanımı sınırlıdır (49). }\end{array}$ & & & \\
\hline $\begin{array}{l}\text { Timpanik } \\
\text { membran }\end{array}$ & $36,5-37,5^{\circ} \mathrm{C}$ & $\begin{array}{l}\text { Timpanik membran, iç vücut } \\
\text { sıcaklığının ölçüm bölgelerinden ve } \\
\text { invazif olmayan yöntemlerden biri } \\
\text { olması, ölçümün kolay ve hızlı } \\
\text { olması ve beynin hipotalamusundaki } \\
\text { termoregülatör merkeze kan sağlayan } \\
\text { iç karotid arterin dallarından kan } \\
\text { alması sebebiyle sıcaklık } \\
\text { değişikliklerine karşı duyarlı ve } \\
\text { güvenilir bir bölge olarak } \\
\text { kullanılmaktadır. İşitme cihazının } \\
\text { olması, timpanik membran ameliyatı } \\
\text { ve kulak kiri bulunması gibi durumda } \\
\text { kullanımı sınırlıdır (24,25). }\end{array}$ & & & \\
\hline
\end{tabular}

Hastanın vücut sıcaklığı normal fakat hasta üşüdüğünü söylüyorsa pasif ısıtma yöntemi kullanılmalıdır (16,22). Vücut sıcaklığı $36^{\circ} \mathrm{C}$ 'nin altında ise aktif 1sıtma yöntemine başlanmalıdır (Şekil 4) $(4,19,21,22)$. Vücut sıcaklığının hangi yolla ölçüldüğünün kayıt edilmesi unutulmamalidir.

Ameliyat sonrası hipoterminin önlenmesine yönelik anestezi sonrası derlenme ünitesinde aktif 1sitma yönteminin kullanıldığı bir randomize kontrollü çalışmada; hastaları ısıtmak için sadece battaniye kullanılan grupta, aktif ısıtma yöntemi kullanılan gruplara kıyasla daha çok kardiyak problem ve titreme olduğu gözlenmiştir. Aynı çalışmada aktif ısıtma yöntemi kullanılan gruplarda $42^{\circ} \mathrm{C}$ ile isitilan grubun, $38^{\circ} \mathrm{C}$ ile isitilan gruba kiyasla normotermi durumlarını daha uzun süre korudukları ortaya çıkmıştır (31). Özsaban ve Acaroğlu'nun (32) yaptığ çalışmada, müdahale grubuna anestezi sonrası derlenme ünitesinde ve yoğun bakım ünitesinde aktif 1sıtma yöntemi kullanılmış, kontrol grubuna ise hastanenin standart uygulaması olan sadece battaniye ile örtme yöntemi kullanılmıştır. Gruplar arasında istatistiksel olarak anlamlı bir fark bulunmuş olup, aktif 1sıtma yönteminin, ameliyat sonrası hipotermide, ısınma süresini kısalttığı ve termal konforda artışı sağladığ belirlenmiştir.
Vücut sıcaklığı normal değer aralığına $\left(36-38^{\circ} \mathrm{C}\right)$ gelen hastanın kliniğe transferi sağlanmalı ve transfer sırasında 1sıtma yöntemi kullanılmaya devam edilmelidir $(4,19,21)$. Hasta klinik hemşiresine teslim edilmeli ve klinik hemşiresine hastaya yapılan termal uygulamalar hakkında bilgi verilmelidir (Şekil 4) (4,16,19-21).

\section{Ameliyat Sonrası Dönem Klinik}

Hasta kliniğe geldiğinde İPH riski (Tablo 1), hipotermi belirti bulguları (Tablo 2) ve üşüyüp üşümediğinin değerlenmesi tekrar yapılmalıdır $(4,16,19,21)$. İH riski veya hipotermi belirti bulguları varsa klinikteki sağlık ekibine haber verilmelidir (4,21). Hasta üşüdüğünü söylüyor fakat vücut sıcaklığı normal değerlerde ise pasif 1sıtma yöntemleri kullanılmalı ve 1sıtma süresi boyunca 4 saatte bir vücut sıcaklığı ölçülmelidir $(16,19)$. Vücut sıcaklığ $136^{\circ} \mathrm{C}$ 'nin altında ise aktif 1 sıtma yöntemine başlanmalı ve 1sitma süresi boyunca her $30 \mathrm{dk}$. 'da bir vücut sıcaklığı ölçülmelidir (Şekil 5) (4,22). Vücut sıcaklığı ölçüm yolu kayıt edilmelidir.

\section{SONUÇ}

İH cerrahi hastalarında yaygın olarak görülen, birçok komplikasyona neden olan fakat önlenebilir bir problemdir. Cerrahi sürecin her aşamasında hastasını değerlendiren hemşireler bu komplikasyonun önlenmesinde kilit rol oynamaktadırlar. $\mathrm{Bu}$ nedenle, hemşirelerin geliştirilen IPH bakım algoritmasını 
kullanarak kanıt düzeyinde bilgilerle ve sistematik bir şekilde IPH risk değerlendirmesini yapması, hipotermi bulgularını değerlendirmesi, hipotermi kaynaklı ortaya çıkabilecek istenmeyen durumlara ilişkin önlemler alması, hastanın termal durumuna göre aktif-pasif ısıtma yöntemlerini kullanması İPH'nin önlenmesine yardımcı olacaktır. Geliştirilen IPH bakım algoritmasının kliniklerde uygulanarak geçerlik güvenirlik çalışmalarının yapılması ve farklı hemşirelik bakımlarına yönelik algoritmaların geliştirilmesi önerilmektedir.

Yazarların Katkıları: Fikir/Kavram: A.G., M.K.,; Tasarım: A.G., M.K.; Veri Toplama ve/veya İşleme: A.G.; Analiz ve/veya Yorum: A.G., M.K. ; Literatür Taraması: A.G.; Makale Yazımı: A.G.; Eleştirel İnceleme: A.G., M.K.

\section{KAYNAKLAR}

1. Sajid MS, Shakir AJ, Khatri K, Baig MK. The role of perioperative warming in surgery: a systematic review. Sao Paulo Medical Journal. 2009; 127(4): 231-7.

2. Sessler DI. Perioperative thermoregulation and heat balance. The Lancet. 2016; 387(10038): 2655-64.

3. Giuliano KK, Hendricks J. Inadvertent perioperative hypothermia: current nursing knowledge. Aorn Journal. 2017; 105(5): 453-63.

4. Nice.org.uk [Internet]. United Kingdom: National Institute for Health and Clinical Excellence; $2008 \mathrm{Apr}$ 23 [Updated: 2016 Dec 14; Cited: 2020 Sep 01]. Available from: www.nice.org.uk: https://www.nice.org.uk/guidance/cg65.

5. Bilgin $H$. Inadverdent perioperative hypothermia. Turkish Journal of Anaesthesiology and Reanimation. 2017; 45(3): 124.

6. Scholten R, Leijtens B, Kremers K, Snoeck M, Koëter $\mathrm{S}$. The incidence of mild hypothermia after total knee or hip arthroplasty: a study of 2600 patients. Journal of orthopaedics. 2018; 15(2): 408-11.

7. Yi J, Xiang Z, Deng X, Fan T, Fu R, Geng W, et al. (2015). Incidence of inadvertent intraoperative hypothermia and its risk factors in patients undergoing general anesthesia in Beijing: a prospective regional survey. Plos One. 2015; 10(9): e0136136.

8. Frisch NB, Pepper AM, Rooney E, Silverton C. Intraoperative hypothermia in total hip and knee arthroplasty. Orthopedics. 2017; 40(1): 56-63.

9. Ralph N, Gow J, Conway A, Duff J, Edward K-L, Alexander K, et al. Costs of inadvertent perioperative hypothermia in Australia: a cost-of-illness study. Collegian. 2019; 27(4): 345-51.

10. Yüksel S, Uğraş GA. Cerrahi hastasında hipotermi gelişimini önlemede hemşirenin rolü. Mersin Üniversitesi Sağlık Bilimleri Dergisi. 2016; 9(2): 11321.

11. Tamer F, Karadağ M. Cerrahi hemşirelerinin istenmeyen perioperatif hipotermi bakımına yönelik bilgi ve uygulamalarının belirlenmesi. Türkiye Klinikleri Hemşirelik Bilimleri. 2020; 12(1): 19-29.

12. RycroftMalone J, Fontenla M, Seers K, Bick D. Protocol- based care: the standardisation of decision making? Journal of Clinical Nursing. 2009; 18(10): 1490-500.

13. Dickerson SS, Sackett K, Jones JM, Brewer C. Guidelines for evaluating tools for clinical decision making. Nurse Educator. 2001; 26(5): 215-20.

14. Hye-rim J, Dong-Hee K. Development of algorithm for nursing interventions after percutaneous coronary intervention. Journal of Korean Academy of Fundamentals of Nursing. 2017; 24(1): 18-29.

15. Park Y, Oh S, Chang H, Bang HL. Effects of the evidence-based nursing care algorithm of dysphagia for nursing home residents. Journal of gerontological nursing. 2015; 41(11): 30-9.

16. Hooper VD, Chard R, Clifford T, Fetzer S, Fossum S, Godden B, et al. Aspan's evidence-based clinical practice guideline for the promotion of perioperative normothermia. J Perianesth Nurs. 2010; 25(6): 34665.

17. Campbell G, Alderson P, Smith AF, Warttig S. Warming of intravenous and irrigation fluids for preventing inadvertent perioperative hypothermia (Review). Cochrane Database of Systematic Reviews. 2015 (4).

18. Madrid E, Urrutia G, Figuls MR, Pardo Hernandez H, Campos JM, Paniagua P, et al. Active body surface warming systems for preventing complications caused by inadvertent perioperative hypothermia in adults. Cochrane Database of Systematic Reviews. 2016 (4).

19. İPHÖ Rehberi, İstenmeyen perioperatif hipoterminin önlemesi. Türk anesteziyoloji ve reanimasyon derneği. Turk J Anaesth Reanim. 2013; 41:188-90.

20. Torossian A, Bräuer A, Höcker J, Bein B, Wulf H, Horn E-P. Preventing inadvertent perioperative hypothermia. Deutsches Ärzteblatt International. 2015; 112(10): 166.

21. Bashaw MA. Guideline implementation: preventing hypothermia. Aorn Journal. 2016; 103(3): 304-13.

22. Lisa C. Guideline for prevention of hypothermia. Aorn Journal. 2019; 110(1): 8-10.

23. Sessler DI. Temperature monitoring and perioperative thermoregulation. Anesthesiology: The Journal of the American Society of Anesthesiologists. 2008; 109(2): 318-38.

24. Yeoh WK, Lee JKW, Lim HY, Gan CW, Liang W, Tan KK. Re-visiting the tympanic membrane vicinity as core body temperature measurement site. Plos One. 2017; 12(4): 0174120.

25. Salota V, Slovakova Z, Panes C, Nundlall A, Goonasekera C. Is postoperative tympanic membrane temperature measurement effective? British Journal of Nursing. 2016; 25(9): 490-3.

26. Lau A, Lowlaavar N, Cooke EM, West N, German A, Morse DJ, et al. Effect of preoperative warming on intraoperative hypothermia: a randomized-controlled trial. Canadian Journal of Anesthesia. 2018; 65(9):1029-40.

27. Rosenkilde C, Vamosi M, Lauridsen JT, Hasfeldt D. Efficacy of prewarming with a self-warming blanket for the prevention of unintended perioperative hypothermia in patients undergoing hip or knee arthroplasty. Journal of Perianesthesia Nursing. 2017; 32(5): 419-28. 
28. Mogensen CB, Wittenhoff L, Fruerhøj G, Hansen S. Forehead or ear temperature measurement cannot replace rectal measurements, except for screening purposes. BMC Pediatrics. 2018; 18(1): 15.

29. Tamasaki Y, Ueshima H, Yoshiyama S, Higuchi S, Otake H. New tympanic membrane temperature shows good correlation with the esophageal temperature accuracy of a noncontact continuous tympanic thermometer. Open Journal of Anesthesiology. 2019; 9(04): 51.

30. Demirci S, Kartal E, Özcan L. Comparison of body temperature in adult hospitalized patients using axillary and tympanic measurement methods. SAJ Biotechnol. 2019; 6: 101.

31. Xu H, Xu G, Ren C, Liu L, Wei L. Effect of forcedair warming system in prevention of postoperative hypothermia in elderly patients: a prospective controlled trial. Medicine. 2019; 98(22): 15895.

32. Özsaban A, Acaroğlu R. The effect of active warming on postoperative hypothermia on body temperature and thermal comfort: a randomized controlled trial. Journal of PeriAnesthesia Nursing. 2020; 34(4): 4239.

33. Sagiroglu G, Ozturk GA, Baysal A, Turan FN. Inadvertent perioperative hypothermia and important risk factors during major abdominal surgeries. Journal of the College of Physicians and Surgeons Pakistan. 2020; 30(2): 123-8.

34. Demirarslan E. Ameliyat sonrası hipotermi kontrolü. Sağlık Akademisi Kastamonu. 2017; 2(1): 51-70.

35. Shapiro Y, Pandolf KB, Avellini BA, Pimental NA, Goldman RF. Physiological responses of men and women to humid and dry heat. Journal of Applied Physiology. 1980; 49(1): 1-8.

36. Ruetzler K, Kurz A. Consequences of perioperative hypothermia. Handb Clin Neurol. 2018; 157: 687-97.

37. Frank SM, Fleisher LA, Breslow MJ, Higgins MS, Olson KF, Kelly S, et al. Perioperative maintenance of normothermia reduces the incidence of morbid cardiac events: a randomized clinical trial. Jama. 1997; 277(14): 1127-34.

38. Frank SM, Higgins MS, Fleisher LA, Sitzmann JV, Raff H, Breslow MJ. Adrenergic, respiratory, and cardiovascular effects of core cooling in humans. American Journal of Physiology-Regulatory, Integrative and Comparative Physiology. 1997; 272(2): 557-62.

39. Silva JE. Thermogenic mechanisms and their hormonal regulation. Physiological reviews. 2006; 86(2): 435-64.

40. Varan Ö, Gürlek A. Adrenal yetmezlik: tanı ve tedavi algoritması, a sistemik review. Yoğun Bakım Dergisi. 2010; 9(4): 200-7.

41. Anderson GJ, Frazer DM, McLaren GD. Iron absorption and metabolism. Current opinions in Gastroenterology. 2009; 25(2): 129-35.

42. Brigham D, Beard J, Tobin B. Iron and thermoregulation: a review. Critical Reviews in Food Science \& Nutrition. 1996; 36(8): 747-63.

43. Jacobi J, Bircher N, Krinsley J, Agus M, Braithwaite SS, Deutschman C, et al. Guidelines for the use of an insulin infusion for the management of hyperglycemia in critically ill patients. Critical Care Medicine. 2012; 40(12): 3251-76.

44. Forristal C, Van Aarsen K, Columbus M, Wei J, Vogt K, Mal S. Predictors of hypothermia upon trauma center arrival in severe trauma patients transported to hospital via ems. Prehospital Emergency Care. 2020; 24(1): 15-22.

45. Rizzo JA, Rowan MP, Driscoll IR, Chan RK, Chung KK. Perioperative temperature management during burn care. Journal of Burn Care \& Research. 2017; 38(1): 277-83.

46. Woehrle T, Lichtenauer U, Bayer A, Brunner S, Angstwurm M, Schäfer S, et al.Misleading symptoms and successful noninvasive rewarming of a patient with severe hypothermia $\left(23,1^{\circ} \mathrm{C}\right)$. Der Anaesthesist. 2018; 67(12): 931-5.

47. Sarkar S, Donn SM, Bhagat I, Dechert RE, Barks JD. Esophageal and rectal temperatures as estimates of core temperature during therapeutic whole-body hypothermia. The Journal of Pediatrics. 2013; 162(1): 208-10.

48. Huggins R, Glaviano N, Negishi N, Casa DJ, Hertel J. Comparison of rectal and aural core body temperature thermometry in hyperthermic, exercising individuals: a meta-analysis. Journal of Athletic Training. 2012; 47(3): 329-38.

49. Wagner M, Lim-Hing K, Bautista MA, Blaber B, Ryder T, Haymore $\mathrm{J}$, et al. Comparison of a continuous noninvasive temperature to monitor core temperature measures during targeted temperature management. Neurocritical Care. 2020; 6: 1-7. 